\title{
Exploring the factors affecting learners' continuance intention of MOOCs for online collaborative learning: An extended ECM perspective
}

\author{
Zhou Junjie \\ Henan University of Economics and Law, School of E-commerce and Logistics Management
}

\begin{abstract}
The purpose of this paper was to investigate what factors influence learners' continuance intention in massive open online courses (MOOCs) for online collaborative learning. An extended expectation confirmation model (ECM) was adopted as the theoretical foundation. A total of 435 valid samples were collected in mainland China and structural equation model (SEM) approach was adopted. The descriptive statistics show that platforms from abroad, such as Coursera and Khan, are more popular than native ones in mainland China. The empirical results show that the effects of three ECM factors (satisfaction with prior learning experience, confirmation with prior learning experience, and perceived usefulness) are significant. Different factors have different predicting power. Knowledge outcome is the first powerful indicator of learners' continuance intention of MOOCs, followed by social influence, learners' satisfaction with prior learning experience, and performance proficiency. The effects of knowledge outcome, performance proficiency, and social influence are significant, showing the success of extended ECM.
\end{abstract}

\section{Introduction}

With the popularity of Web 2.0, many of our online activities have been reformed. Different from the first generation websites, Web 2.0 websites allow their users to interact and collaborate with each other in a social media dialogue. This user-generated content mechanism makes online collaborative learning become interactive (Yueh, Huang, \& Chang, 2015). For example, users can not only read and learn, but also create and share contents on wiki-type software (Li, 2015; Wheeler, Yeomans, \& Wheeier, 2008; Yueh, Huang, \& Chang., 2015). When engaging on social network sites (SNSs) such as Facebook, students can integrate fragmented information into their educational activities, and thus improve their knowledge outcomes, performance proficiency, and self-esteem (Cheung, Chiu, \& Lee, 2011; Yu, Tian, Vogel, \& Kwok, 2010). The popularity of online collaborative learning has attracted many scholars. They have begun to explore the ways of how students have success in this new learning setting, and why learners keep learning in those online learning communities (Chiu \& Wang, 2008; Stahl, Koschmann, \& Suthers, 2006).

Recently, massive open online courses (MOOCs) have become very popular (Muñoz-Merino, Ruipérez-Valiente, Alario-Hoyos, Pérez-Sanagustín, \& Kloos, 2014; Spoelstra, van Rosmalen, Houtmans, \& Sloep, 2015). As a new online collaborative learning paradigm, MOOCs aim at open education and free access (Catropa, 2013). On the one side, MOOCs providers invite well-established universities and teachers to make online videos and supplemental materials to guarantee the course quality (Alraimi, Zo, \& Ciganek, 2015). On the other side, MOOC providers integrate new communication tools (e.g., instant forums and thread discussions) into their platforms to support mutual communication among learners and instructors. The use of online discussion forums empowers both learners and teachers to emphasise the social aspect of learning and promote in-depth discussions even when they are at different places (Yang, Heinrich, \& Kemp, 2011). In addition, MOOCs are usually free of charge - in some cases attracting only with a small or minimal fee - to obtain a completion certificate. The above advantages assist in MOOCs success in attracting users (Alraimi, Zo, \& Ciganek, 2015; Hew \& Cheung, 2014; Sturges, 2014). Many scholars believe that MOOCs can help to achieve the ultimate democratisation of education, by making education more accessible to as many people as possible (Jacobs, 2013).

Although MOOCs have many prominent advantages, the average completion rate is lower than $10 \%$ (Catropa, 2013). Skeptics even doubt the real learning effects and sustainability for the future (Alraimi, Zo, \& Ciganek, 2015). So, there is an interesting paradox about MOOCs learning. On the one hand, MOOCs are a representation of those course qualifications. On the other hand, few learners complete their enrolled courses, making the continuance of MOOCs become a problem. Thus we are curious about what are the factors influencing the learners' continuance intention in MOOCs. This paper aims to answer this question. 


\section{Literature review}

The year 2012 is called MOOCs year (Jacobs, 2013). Those famous platforms such as Coursera, edX, Udacity, and KHANACADEMY, all rose up in 2012 and quickly attracted lots of users. Take Coursera for example. During its first several months, it attracted more than 30 university partners including Princeton, Brown, Columbia, Duke, Stanford, and Johns Hopkins, registered 2.8 million students, and saw 1.4 million course enrollments every month (Cusumano, 2013; Hew \& Cheung, 2014).

This trend triggered a hot discussion about the relationship between MOOCs and traditional education. Some scholars hold that MOOCs are open platforms and everyone can access them if they wish (Jacobs, 2013). In their eyes, openness will oblige universities to revisit their business models and missions, and then focus on teaching quality and students as never before (Daniel, 2012). They thus believe that MOOCs will flip our traditional classroom, and some higher education institutions will definitely disappear if they continue to embrace the status quo (Lucas, 2013).

Alongside the cited advantages, there are also many criticisms of MOOCs, one of them being its dismal completion rates. Reports indicate that the completion rates of MOOCs are usually lower than 10\%, with a steep participation drop in the first week; even steeper in the first few days (Catropa, 2013). For example, in the bioelectricity course, offered at Duke University during the fall of 2012, 12,725 students enrolled, but only 7,761 watched a video, 3,658 attempted a quiz, 345 attempted the final exam, and 313 passed and earned a certificate (Catropa, 2013). The low completion rates mean that there are limited active learners participating in MOOCs learning. This is a substantial problem, because user participation is an important indicator to measure the sustainability of virtual communities (Chang \& Chen, 2014; Zhou, Zuo, Yu, \& Chai, 2014). Scholars are thus curious about MOOCs' effectiveness and sustainability in their early stages (Alraimi, Zo, \& Ciganek, 2015). So, what are the factors influencing learners' continuance intention of MOOCs?

Only a few papers have addressed this topic. Alraimi et al. (2015) think that MOOCs have two significant characteristics: openness and reputation. They examined the effects of the two characteristics and other factors, and found that perceived reputation is the strongest predictor for learners' intention to continue using MOOCs, followed by perceived openness, perceived usefulness, and perceived enjoyment (Alraimi, Zo, \& Ciganek, 2015). However, they didn’t pay much attention to the learning outcomes of MOOCs. Others find that MOOCs learning lacks face-to-face engagement, which introduces a sense of isolation in students, resulting in a high dropout rate (Chen, Phang, Zhang, \& Cai, 2016). However, if the online forum encourages their learners to interact with each other, leaners will have more incentives to continue MOOCs learning (Chen, Phang, Zhang, \& Cai, 2016). In addition, learning via MOOCs belongs to the self-regulated learning paradigm. Autonomous motivation or self-organised, offline learning groups are helpful for learners to achieve better learning outcomes (Santhanam, Sasidharan, \& Webster, 2008; Zhou, 2016). Prior findings offer lots of insights. However, more effort needs to pay to this topic.

\section{Theoretical foundation}

\section{Continuance intention of technology: The expectation confirmation model}

ECM is sourced from expectation confirmation theory (ECT). ECT is a theory in marketing and posits that expectations, coupled with perceived performance, leads to consumers' post-purchase satisfaction (Oliver, 1980; Spreng, MacKenzie, \& Olshavsky, 1996). This effect is mediated by consumers' confirmation of prior purchase experience. When consumers' confirmation is positive, they will continue to purchase; otherwise they will stop. Bhattacherjee (2001a) extended ECT and brought it into information systems (IS) discipline (see Figure 1).

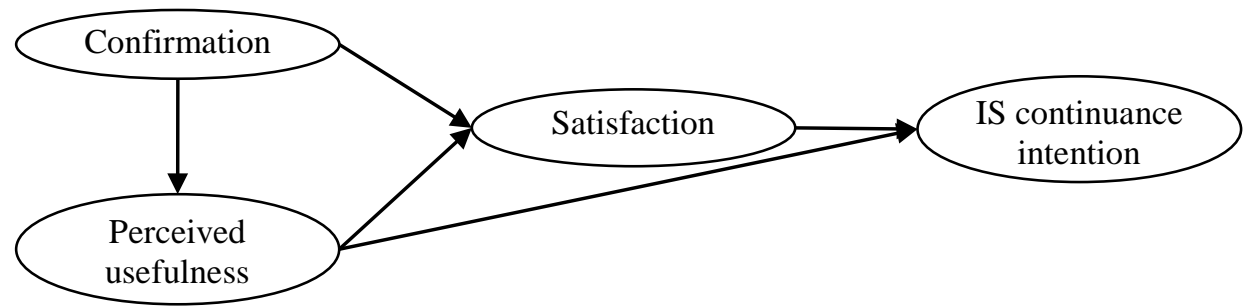

Figure 1. Expectation confirmation model 
Bhattacherjee's model posits that users' confirmation of prior IS use, coupled with post-adoption perceived usefulness, leads to users' IS continuance intention. This effect is partially mediated by users' satisfaction. ECM has shown its power in explaining users' IS continuance intention during the past decades. It was frequently used to explain why people continuingly use online banks (Bhattacherjee, 2001b), or their intention to reuse a web site (Lin, Wu, \& Tsai, 2005).

Recently, ECM has extended into the e-learning discipline. For example, Lee (2010) synthesises the expectation-confirmation model, the technology acceptance model, the theory of planned behavior, and the flow theory to predict the users' intentions to continue using e-learning. Empirical results show that satisfaction has the most significant effect on users' continuance intention, followed by perceived usefulness, attitude, concentration, subjective norm, and perceived behavior control as significant but weaker predictors (Lee, 2010). Chow and Shi (2014) examined the ECM factors of post-adoption expectation by students' post-adoption experiences in e-learning, and found that learning process and course design are the two factors that have a direct influence on both learners' satisfaction and continuance intention. Alraimi et al. (2015) extended ECM to explain learners' continuance intention of MOOCs, and find that perceived reputation, perceived openness, perceived usefulness, perceived, and user satisfaction are significant predictors. The above studies have added new constructs (e.g., concentration, subjective norm, reputation, or openness) to ECM and extended the theory into e-learning settings, indicating that ECM is an appropriate theoretical foundation to explain learners' MOOCs use. Therefore, we follow their approaches and adopt ECM as the theoretical foundation in this paper.

\section{Perceived usefulness and learning outcomes}

Perceived usefulness is a key construct in ECM, and captures the instrumentality of IS use (Bhattacherjee, 2001a). Specific to the context of MOOCs, perceived usefulness refers to the degree to which a learner believes that learning via MOOCs would enhance his or her job/learning performance (Venkatesh, Morris, Davis, \& Davis, 2003). However, perceived usefulness is a broad construct, and cannot capture the specific instrumentality of MOOCs learning. This paper uses the learning outcomes as a replacement.

Unlike face-to-face courses, e-learning is completed online and lacks the non-verbal cues of eye contact, movement, and body position (Proserpio \& Magni, 2012). This difference drives scholars to explore the e-learning outcomes. They have divided e-learning outcomes into three domains: cognitive outcomes, skill-based outcomes, and affective outcomes (Wan, Compeau, \& Haggerty, 2012; Yu, Tian, Vogel, \& Kwok, 2010). Cognitive outcomes refer to outcomes related with knowledge: knowledge, comprehension, and application (Wei, Teo, Chan, \& Tan, 2011). Skill-based outcomes refer to the capabilities of how to use knowledge or the improved performance caused by knowledge application: critical thinking and technical skills to solve problems or perform tasks (Yu, Tian, Vogel, \& Kwok, 2010). Affective outcomes refer to learners' mental state: learners' attitudes, satisfaction, and appreciation of their learning experience (Yu, Tian, Vogel, \& Kwok , 2010). Cognitive outcome and skill-based outcome describe the instrumental attribute of e-learning. Following the prior research on e-learning (Yu, Tian, Vogel, \& Kwok, 2010), we adopt knowledge outcome and performance proficiency as the specific replacement for perceived usefulness in ECM.

\section{The extended ECM for learners' continuance intention of MOOCs}

As shown in Figure 1, the focus in ECM is users' prior use experience. We treat continuance use as a sequence of repeated behaviours. There should be some other factors that influence users' continuance intention, for example the opinions of important individuals (social influence) (Lee, 2010). In this paper, we first integrate social influence as an extension of ECM. Social influence refers to the degree to which a learner believes that others think he/she should continue to learn through MOOCs (Venkatesh, Morris, Davis, \& Davis, 2003). We then use knowledge outcome and performance proficiency as a replacement for perceived usefulness to describe learners' motivation of continuing use.

According to ECM, learners' satisfaction with prior learning experience, knowledge outcome and performance proficiency as expected learning outcomes, and social influence are posited to directly influence learners' continuance intention of MOOCs. Their confirmation with prior learning experience will indirectly influence their continuance intention through the mediating roles of the satisfaction with prior learning experience and the expected learning outcomes (see Figure 2). 


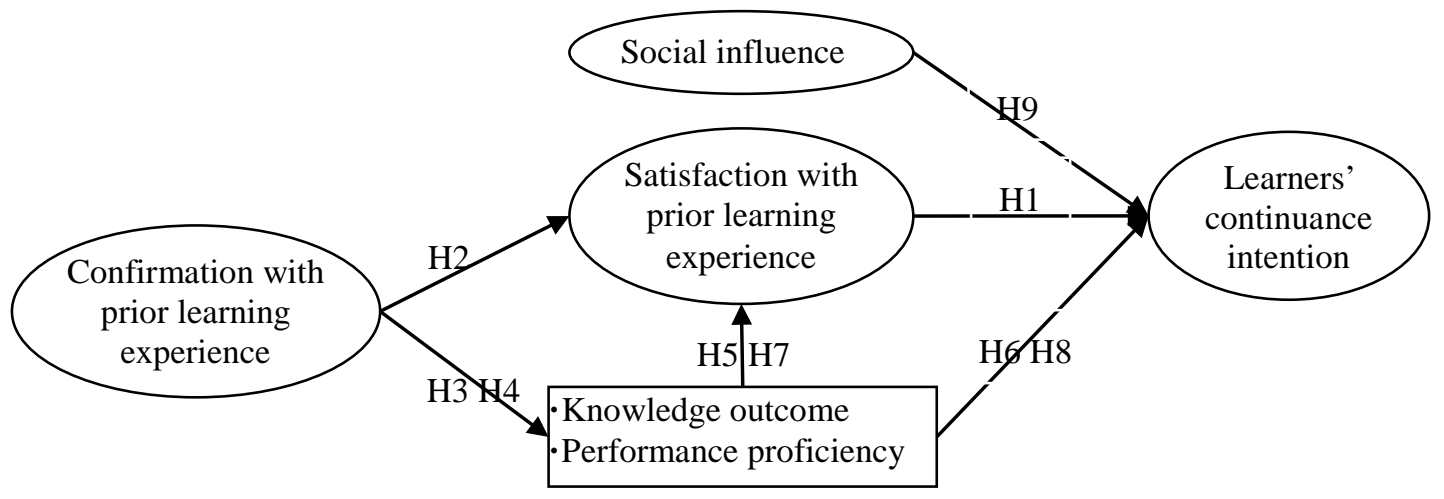

Figure 2. Extended ECM for learners’ continuance intention of MOOCs

\section{Satisfaction with prior learning experience}

Satisfaction is a key construct in ECM. According to ECM, users' continuance intention of IS use is determined by two constructs: their satisfaction with prior use experience and post-adoption expectation of future use (Bhattacherjee, 2001a). The positive relationship between users' satisfaction and their continuance intention of a specific IS has been verified in prior studies (Alraimi, Zo, \& Ciganek, 2015; Chiu, Hsu, Sun, Lin, \& Sun, 2005; Lee, 2010; Lin, Wu, \& Tsai, 2005). Specific to MOOCs, satisfaction refers to the learners' perception of enjoyment and accomplishment in learning environment (Alraimi, Zo, \& Ciganek, 2015). If learners feel satisfied with MOOCs, they will have stronger intention to continue usage. Hence, we hypothesise:

H1: MOOCs learners' satisfaction with prior learning experience positively influences their continuance intention.

\section{Confirmation with prior learning experience}

Confirmation refers to the users' perception of the congruence between their expectation of IS use and its actual performance (Bhattacherjee, 2001a). ECT and ECM posit that users' satisfaction with IS use is determined by two constructs: confirmation of prior use experience and expected performance of future continued use (or perceived usefulness). The positive relationship between users' confirmation and their satisfaction also has been confirmed in prior research (Alraimi, Zo, \& Ciganek, 2015; Chiu, Hsu, Sun, Lin, \& Sun, 2005; Lee, 2010). When users feel that their actual performance overcomes their prior expectation, their confirmation will be positive. This positive confirmation will thus result in higher-level satisfaction. When they feel that their actual performance is worse than their prior expectation, their confirmation will be negative. This negative confirmation will thus result in lower-level satisfaction. Specific to MOOCs learning, when learners' actual performance overcomes their prior expectation, they will be satisfied with their prior learning experience. Hence, we hypothesise:

H2: Learners' confirmation of prior learning experience positively influences their satisfaction with MOOCs learning.

In ECM, perceived usefulness describes users' expectation about the future, after their initial use (Bhattacherjee, 2001a). This post-adoption expectation is positively associated with the confirmation extent of their prior use experience (Lee, 2010). When their prior expectation is confirmed, they will feel the system is worth using and will expect more in their future use. Specific to the MOOC context, leaners' confirmation of prior learning experience will enhance their expectation about future learning. In learners' eyes, because they are supported by well-established universities or teachers, MOOCs platforms usually have good reputation (Alraimi, Zo, \& Ciganek, 2015). Learning via MOOCs can extend their knowledge scope on certain topics or domains (Hew \& Cheung, 2014). When they meet difficulties during their learning process, they can turn to other leaners or instructors (Catropa, 2013) to improve their capabilities of applying knowledge (i.e., performance proficiency). Hence, we hypothesise:

H3: Learners' confirmation of prior learning experience positively influences their knowledge outcome expectation about future use. 
H4: Learners' confirmation of prior learning experience positively influences their performance proficiency expectation about future use.

\section{Knowledge outcome and performance proficiency}

Knowledge outcome refers to the learners' perception of subject matter understanding (Alavi, George, \& Yoo, 2002), for example the scope, knowledge, and academic results in relation to certain issues. In learners' eyes, MOOCs are bridges to a new learning world. They can extend their knowledge scope via MOOCs learning (Hew \& Cheung, 2014). The more knowledge they believe they will obtain from MOOCs, the more possibility will they feel satisfaction with MOOCs and choose to continue usage in future. Hence, we hypothesise:

H5: Learners' knowledge outcome about future use positively influences their satisfaction with MOOCs.

H6: Learners' knowledge outcome about future use positively influences their continuance intention of MOOCs.

Performance proficiency refers to how well an individual masters the required knowledge, skills, and abilities (Chao, O'Leary-Kelly, Wolf, Klein, \& Gardner, 1994). Different from prior online courses, MOOC providers have integrated new instant communication tools into their platforms. Learners can thus communicate with other learners and instructors. This synchronous communication can help learners to tackle their learning problems and better understand their courses. For learners, the more they believe that learning via MOOCs can improve their performance, the more possibility that will they feel satisfaction with MOOCs and choose to continue using MOOCs in the future. Hence, we hypothesise:

H7: Learners’ performance proficiency about future use positively influences their satisfaction with MOOCs.

H8: Learners' performance proficiency about future use positively influences their continuance intention of MOOCs.

\section{Social influence}

Social influence is a powerful indicator of individuals' IS use intention (Venkatesh, Morris, Davis, \& Davis, 2003; Yang, Lu, Gupta, Cao, \& Zhang, 2012). It can be divided into two parts: external and interpersonal influences (Bhattacherjee, 2000). External social influence includes mass media reports, expert opinions, and other non-personal information. Interpersonal social influence includes word-of-mouth from friends, colleagues, and superiors. People tend to interact with others for suggestions and consultation to reduce potential uncertainty and anxiety, when facing new situations (Karahanna, Straub, \& Chernanv, 1999). Their decisions are affected via the word-of-mouth from media and people around them. For new to MOOC users, it is a new learning experience. They will pay much attention to suggestion from media reports and people around them. Hence, we hypothesise:

H9: Social influence positively influences the learners’ continuance intention of MOOCs.

\section{Methodology}

\section{Constructs and scales}

We adopted a survey approach to test our research model. All scales were adopted from prior research and modified according to our MOOCs context (see Appendix 1). Considering our questionnaire was in Chinese, while all measures were originally developed in English, we took the following precautions to improve the survey quality. First, we invited two $\mathrm{PhD}$ candidates who are Chinese-English bilinguals to do back-and-forth translation. The translation revision process was continued until the meanings of all constructs in Chinese and English converged. Second, we invited a professor who had ample scale development experience and asked her to check the content validity. Third, we invited six students who had MOOC learning experience to complete the questionnaire. During the process, we asked them to identify any confusing questions and then modified these accordingly. The questionnaire was finalised when the back-and-forth translation and the pilot test were complete. All questions were structured using a 7-point Likert scale, ranging from 1 (absolutely disagree) to 7 (absolutely agree). 


\section{Data collection}

We carried out an online survey via sojump.com (a Chinese website similar with qualtrics.com). The questionnaire link was distributed among MOOCs forums and QQ (the most popular instant message tool provided by Tencent in China) groups for MOOCs. We informed participants that all the data would be solely used for academic research, and their privacy information well protected. We took several further precautions to ensure appropriateness in our sampling. First, each IP address was allowed only once. Second, 50 lottery e-gifts were randomly drawn from the particpants' surveys. Third, three questions: “Which MOOC platforms do you use?”, "How many previous courses have you enrolled in?”, and "How many previous courses have you completed?” were added to check whether the participants had real MOOC learning experiences or not. The questionnaire was open for 45 days (from September 12 to October 26 in 2014). We collected 435 valid samples with the guarantee of these measures. The demographic profile of all samples is shown in Table 1.

Table 1

Descriptive statistics

\begin{tabular}{|c|c|c|c|c|c|c|c|}
\hline MOOCs platforms & $\mathrm{N}$ & Gender & $\mathrm{N}$ & Per. (\%) & Age & $\mathrm{N}$ & Per. $(\%)$ \\
\hline Coursera & 249 & Female & 189 & 43.4 & $\leq 18$ & 15 & 3.4 \\
\hline MOOC.cn & 231 & Male & 246 & 56.6 & {$[19,24]$} & 263 & 60.5 \\
\hline KHANACADEMY & 112 & Career & $\mathrm{N}$ & Per. $(\%)$ & {$[25,30]$} & 102 & 23.4 \\
\hline edX & 103 & Student & 290 & 66.7 & {$[31,36]$} & 30 & 6.9 \\
\hline imooc.cn & 82 & General staff & 38 & 8.7 & $\geq 37$ & 25 & 5.7 \\
\hline xuetangx.com & 75 & Professional & 33 & 7.6 & Education* & $\mathrm{N}$ & Per. $(\%)$ \\
\hline moocs.org.cn & 74 & Teacher & 31 & 7.1 & Postgraduate & 164 & 37.7 \\
\hline Udacity & 26 & Manager & 14 & 3.2 & Bachelor & 241 & 55.4 \\
\hline Others & 34 & Others* & 29 & 6.7 & College and below & 30 & 6.9 \\
\hline
\end{tabular}

Note: The question about MOOC platforms was multi-choice; “Others*” in career includes choices that numbered less than 10; "Education*” includes students still in school.

Table 1 indicates several pieces of useful information. First, foreign platforms such as Coursera, KHANACADEMY, and $e d X$ are much more popular than the native platforms, for example MOOC.cn and imooc.cn. Native MOOC platforms still have much scope for improvement. Second, the gender rate is very close to the official data (female: 43.6\%) reported by China Internet Network Information Center. Third, MOOC users are usually well educated. The majority of them are students in universities.

All the data were collected through self-report. Common method bias caused by a single-information method might have posed a problem (Howard, 1994). We took several precautions to minimise the potential common method bias (Podsakoff, MacKenzie, Lee, \& Podsakoff, 2003). First, each IP address was allowed only once. Second, all items were randomly dispersed. Third, two irrelevant questions were added. Finally, we relied on Harman's single-factor method to assess the common method bias statistically. In fact, the first factor only captured $14.38 \%$, indicating that the variance did not merely stem from one factor. Overall, the data did not suffer from a severe problem of common method bias.

\section{Measurement model assessment}

The scale's convergent and discriminant validity was tested by explorative factor analysis and confirmative factor analysis. We conducted all the analysis based on SPSS 20 and AMOS 21. Table 2 shows the factor loadings and their relative Cronbach's $\alpha$ value. Table 3 shows the correlations among different factors. 
Table 2

Factor loadings

\begin{tabular}{|c|c|c|c|c|c|c|c|}
\hline & CPLE & KO & PP & SATIS & SI & LCI & Sources \\
\hline CPLE1 & .676 & .150 & .256 & .326 & .230 & .252 & \multirow{3}{*}{$\begin{array}{c}\text { (Alraimi, Zo, \& } \\
\text { Ciganek, 2015) }\end{array}$} \\
\hline CPLE2 & .756 & 191 & .191 & .240 & .256 & .298 & \\
\hline CPLE3 & .738 & .182 & .228 & .310 & .178 & .295 & \\
\hline KO1 & .143 & .783 & .142 & .142 & .231 & .389 & \multirow{4}{*}{$\begin{array}{l}\text { ( Wei, Teo, Chan, } \\
\text { \& Tan, 2011) }\end{array}$} \\
\hline $\mathrm{KO} 2$ & .157 & .765 & .099 & .162 & .272 & .369 & \\
\hline KO3 & .147 & .807 & .161 & .172 & .237 & .167 & \\
\hline PP1 & .104 & .080 & .777 & .130 & .326 & .176 & \\
\hline PP2 & .162 & .214 & .740 & .115 & .244 & .203 & \multirow{3}{*}{$\begin{array}{l}\text { ( Yu, Tian, Vogel, } \\
\text { \& Kwok, 2010) }\end{array}$} \\
\hline PP3 & .121 & .125 & .815 & .240 & 126 & .080 & \\
\hline PP4 & .192 & .036 & .775 & .277 & .085 & .044 & \\
\hline SATIS1 & .177 & .220 & .355 & .672 & .290 & .239 & \multirow{4}{*}{$\begin{array}{l}\text { ( Yu, Tian, Vogel, } \\
\text { \& Kwok, 2010) }\end{array}$} \\
\hline SATIS2 & .253 & .176 & .265 & .734 & .272 & .213 & \\
\hline SATIS3 & .283 & .114 & .245 & .677 & .239 & .339 & \\
\hline SATIS4 & .314 & .180 & .236 & .655 & .226 & .280 & \\
\hline SI1 & .148 & .285 & .215 & .119 & .709 & .353 & \multirow{4}{*}{$\begin{array}{c}\text { (Yang, Lu, Gupta, } \\
\text { Cao, \& Zhang, } \\
\text { 2012) }\end{array}$} \\
\hline SI2 & .185 & .234 & .169 & .208 & .780 & .233 & \\
\hline SI3 & .154 & .210 & .258 & .235 & .735 & .205 & \\
\hline SI4 & .167 & 152 & 204 & .246 & .780 & 199 & \\
\hline LCI1 & .178 & .228 & .103 & .194 & .296 & .806 & \multirow{4}{*}{$\begin{array}{c}\text { (Alraimi, Zo, \& } \\
\text { Ciganek, 2015) }\end{array}$} \\
\hline LCI 2 & .206 & .241 & .116 & .145 & .253 & .834 & \\
\hline LCI 3 & .205 & .211 & .144 & .174 & .181 & .786 & \\
\hline LCI 4 & .166 & .216 & .144 & .289 & .165 & .792 & \\
\hline Cronbach's $\alpha$ & .916 & .922 & .906 & .928 & .949 & .949 & -- \\
\hline
\end{tabular}

Note: CPLE, KO, PP, SATIS, SI, and LCI respectively, are short for confirmation with prior learning experience, knowledge outcome, performance proficiency, satisfaction with prior learning experience, social influence, and learners’ continuance intention.

Table 3

Correlation matrix

\begin{tabular}{lcccccccccc}
\hline & Mean & S.E. & C.R. & AVE & CPL & KO & PP & SATIS & SI & LCI \\
\hline CPLE & 5.01 & .121 & .917 & .787 & $\mathbf{. 8 8 7}$ & & & & & \\
KO & 5.70 & .110 & .925 & .806 & .566 & $\mathbf{. 8 9 8}$ & & & & \\
PP & 5.00 & .121 & .898 & .687 & .576 & .445 & $\mathbf{. 8 2 9}$ & & & \\
SATIS & 4.81 & .116 & .923 & .748 & .751 & .568 & .642 & $\mathbf{. 8 6 5}$ & & \\
SI & 5.43 & .133 & .919 & .740 & .631 & .645 & .581 & .678 & $\mathbf{. 8 6 0}$ & \\
LCI & 5.72 & .117 & .947 & .817 & .656 & .669 & .449 & .650 & .641 & $\mathbf{. 9 0 4}$ \\
\hline
\end{tabular}

The content validity was assessed by the average variance extraction (AVE) values. As shown in Table 3, all AVE values are higher than 0.5, showing that most variance was successfully extracted.

The convergent validity was assessed by two approaches. The first one was the factor loading. As shown in Table 2, all the loadings wewre greater than 0.6 in their respective factor. The second included Cronbach's $\alpha$ and composite reliability. Nunnally (2010) suggests that a minimum alpha of 0.6 suffices for early stages of research. As shown in Table 2 and 3, all Cronbach's $\alpha$ values were higher than 0.877 , and all composite reliability values were greater than 0.871 , indicating good convergent validity.

The discriminant validity was assessed by two approaches. The first one was the factor loading. As shown in Table 2, all the item loadings in their respective factors were greater than the values in their irrespective factors, showing good discriminant validity. The second approach was a comparison between correlation values and AVE square root. As shown in Table 3, the values on the dialog line are AVE square root, while the values on the non-dialog lines are correlations among different values. Obviously, the former values were all greater than the latter values, showing good discriminant validity. 


\section{Discussion}

\section{Hypotheses testing}

We first tested the fitness indices of the structural model as shown in Table 4 . The value of $\chi^{2} / d f$ was in the suggested range of 3 to 5 . The value of RMSEA is 0.070 , which is at a reasonable level (Diamantopoulos, Siguaw, \& Siguaw, 2000). The values of GFI and AGFI were around 0.9. Both of them were at the acceptable level (Hu \& Bentler, 1998). The values of CFI and NFI were greater than 0.9, which showed good fit. These indices together indicated a good fitness of the structural model.

Table 4

Fitness indices

\begin{tabular}{cccccccc}
\hline$\chi^{2}$ & $d f$ & $\chi^{2} / d f$ & GFI & AGFI & CFI & NFI & RMSEA \\
\hline 386.059 & 124 & 3.113 & .909 & .874 & .967 & .952 & .070 \\
\hline
\end{tabular}

Figure 3 shows the results of hypotheses test and structural model assessment.

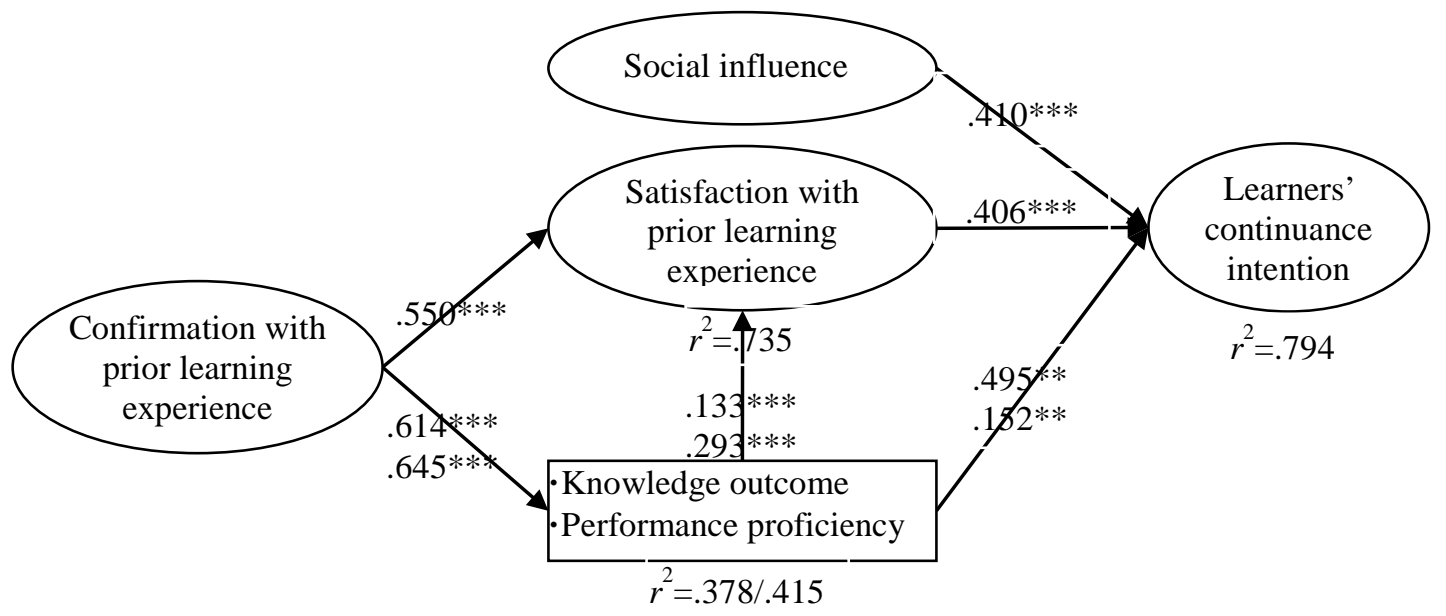

Figure 3. Results of structural model assessment $(* p<0.05$, ** $p<0.01$, *** $p<0.001)$

First, effects of the three key ECM factors were significant. As shown in Figure 3, the direct effects of satisfaction with prior learning experience and perceived usefulness (knowledge outcome and performance proficiency) were significant, so $\mathrm{H} 1, \mathrm{H} 6$, and $\mathrm{H} 8$ were supported. The effects of confirmation with prior learning experience on learners' satisfaction with prior learning experience and perceived usefulness were significant, so H2, H3, and H4 were supported. The effects of perceived usefulness (knowledge outcome and performance proficiency) on learners' satisfaction with prior learning experience were significant, so $\mathrm{H} 5$ and H7 were supported. These above findings show that learners' satisfaction with their MOOCs learning were related to two factors, i.e., their confirmation with prior learning experience and their perceived usefulness (knowledge outcome and performance proficiency).

Second, the extension of ECM was successful. Although previous research has found ECM to be a robust model for continued IT adoption, it has employed only three variables (i.e., satisfaction, confirmation, and post-adoption expectations) to explain behavioral intention (Bhattacherjee, 2001a; Bhattacherjee, 2001b). However, a user's behavioral intention toward adopting IT will also be affected by other factors (Lee, 2010). Specific to the MOOCs context, we used knowledge outcome and performance proficiency as a replacement of perceived usefulness, and integrated social influence into the model to capture other influencing factors. As shown in Figure 3, the effects of social influence, knowledge outcome, and performance proficiency were significant, so H6, H8, and H9 were supported. This endeavor successfully captured the characteristics of MOOCs, and extended ECM into the MOOCs learning context.

Third, different factors have different predicting power on learners' continuance intention. As shown in Figure 3, knowledge outcome has the most significant effect on learners' continuance intention, followed by social influence, satisfaction with prior learning experience, and performance proficiency. This indicates that, the first reason driving learners to continue MOOCs learning is the course quality. Learners 
believe that learning via MOOCs can improve their knowledge scope, so they choose to continue. This finding is different from prior research. For example, some scholars found that perceived reputation is the strongest predictor for learners' intention to continue using MOOCs, followed by perceived openness, perceived usefulness, and perceived enjoyment (Alraimi, Zo, \& Ciganek, 2015). In our opinion, reputation is a superficial factor. The reputation of MOOCs is based on the course quality and the course providers (well-established universities and teachers). So, compared with reputation, the expected knowledge outcome as the most predicting factor is a more reasonable finding.

\section{Contributions for research}

This research has two significant theoretical contributions. First, we integrated three new constructs and extended the ECM model into online learning discipline. ECM focuses on users' prior learning experience. In this paper, we first integrated social influence into the model as an extension, and then used learning outcomes (i.e., knowledge outcome and performance proficiency) as a replacement of perceived usefulness. This extends the ECM into MOOCs context. The empirical results supported all the hypotheses, indicating a successful extension of ECM. This will contribute to future research on ECM and MOOCs learning.

Second, we found that different antecedents have different predicting power. In this paper, we used learning outcomes to replace the perceived usefulness, and then divided learning outcomes into knowledge outcome and performance proficiency. The empirical results showed that knowledge outcome is the first powerful indicator of learners' continuance intention of MOOCs, followed by social influence, learners' satisfaction with prior learning experience, and performance proficiency. This finding attributes learners' continuance intention of MOOCs to the knowledge outcome (i.e., course quality) and other factors. This is different from other studies. For example Lee (2010) found that satisfaction has the most significant effect on users' continuance intention, while other scholars found that perceived reputation is the strongest predictor for learners’ intention to continue using MOOCs (Alraimi, Zo, \& Ciganek, 2015). This research provides an alternative answer, and will drive more scholars to pay attention to this topic.

\section{Implications for practice}

This paper explored the factors influencing learners' continuance intention of MOOCs, and showed its practical implications for MOOC promotion. First, MOOC platforms should provide qualified courses. The empirical results showed that knowledge outcome is the first powerful indicator of learners' continuance intention of MOOCs, followed by social influence, learners' satisfaction with prior learning experience, and performance proficiency. So, MOOC providers should attract more universities and teachers to provide more qualified courses. Those qualified courses are the guarantee of learners' continuance intention and satisfaction.

Second, MOOC providers should carefully market their platforms. As the empirical results showed, social influence is a powerful indicator of learners' continuance intention of MOOCs. Social influence includes the external social influence such as mass media reports or expert opinions, and interpersonal social influence such as word-of-mouth from friends, colleagues, or superiors. On one hand, MOOC platforms can market via online websites or other channels to let more users know their platform. On the other hand, they can try to find those exemplar learners, and show them as public examples to attract more users to use MOOCs.

\section{Conclusions}

Using MOOCs, this paper investigates the factors influencing learners' continuance intention of online collaborative learning. We extended the ECM by integrating social influence as the external factor, and used knowledge outcome and performance proficiency as a replacement of perceived usefulness. The descriptive statistics results showed that MOOC platforms from abroad are more popular than the native ones in China. Students in universities are the biggest using group of MOOCs in China. The empirical results showed that the effects of three ECM factors (satisfaction with prior learning experience, confirmation with prior learning experience, and perceived usefulness) were all significant. The effects of knowledge outcome, performance proficiency, and social influence were all significant, so the extension of ECM was successful. 
We acknowledge two limitations to our study that suggest the need for future research. First, we collected our data from at least eight MOOCs platforms, including both abroad and native platforms. Courses on platforms from abroad are usually in English, while native courses are usually in Chinese. We are not sure whether this difference will influence learners' satisfaction and continuance intention or not. If possible, platform types should be taken into consideration when investigating learners' satisfaction with and continuance intention of MOOCs. Second, we didn't consider course disciplines and their impacts on learners' satisfaction and continuance intention. It seems that courses in business, art, and psychology are usually more popular than courses in health, engineering, and science. We are not sure whether course types could influence learners' satisfaction or not. If possible, discipline types should be taken into consideration.

\section{Acknowledgements}

This work is supported by National Natural Science Foundation of China (71501062), Young Talents Fund of HUEL (hncjzfdxqnbjrc201603), and Discipline Enhancing Program Fund of Henan University (Y1512001). The author sincerely appreciates two QQ groups (Group ID: 310851773 and 192604650) who devote their efforts in idea exchanging and data collecting during this research.

\section{References}

Alavi, M., George, M. M., \& Yoo, Y. (2002). A comparative study of distributed learning environments on learning outcomes. Information Systems Research, 13(4), 404-415. https://doi.org/10.1287/isre.13.4.404.72

Alraimi, K., Zo, H., \& Ciganek, A. (2015). Understanding the MOOCs continuance: The role of openness and reputation. Computers \& Education, 80(1), 28-38. https://doi.org/10.1016/j.compedu.2014.08.006

Bhattacherjee, A. (2000). Acceptance of e-commerce services: the case of electronic brokerages. IEEE Transactions on Systems, Man, and Cybernetics - Part A: Systems and Humans, 30(4), 411-420. https://doi.org/10.1109/3468.852435

Bhattacherjee, A. (2001a). Understanding information systems continuance: An expectation-confirmation model. MIS Quarterly, 25(3), 351-370. https://doi.org/10.2307/3250921

Bhattacherjee, A. (2001b). An empirical analysis of the antecedents of electronic commerce service continuance. Decision Support Systems, 32(2), 201-214. https://doi.org/10.1016/S0167-9236(01)00111-7

Catropa, D. (2013). Big (MOOC) data. Retrieved from https://www.insidehighered.com/blogs/stratedgy/big-mooc-data

Chang, L., \& Chen, J. V. (2014). Aligning principal and agent's incentives: A principal - agent perspective of social networking sites. Expert Systems with Applications, 41(6), 3091-3104. https://doi.org/10.1016/j.eswa.2013.10.040

Chao, G. T., O'Leary-Kelly, A. M., Wolf, S., Klein, H. J., \& Gardner, P. D. (1994). Organizational socialization: Its content and consequences. Journal of Applied Psychology, 79(5), 730-743. https://doi.org/10.1037/0021-9010.79.5.730

Chen, H., Phang, C. W., Zhang, C., \& Cai, S. (2016). What kinds of forum activities are important for promoting learning continuance in MOOCs? Paper presented at the Pacific Asia Conference on Information Systems, Chiayi, Taiwan. Retrieved from http://aisel.aisnet.org/pacis2016/51

Cheung, C. M., Chiu, P., \& Lee, M. K. (2011). Online social networks: Why do students use Facebook? Computers in Human Behavior, 27(4), 1337-1343. https://doi.org/10.1016/j.chb.2010.07.028

Chiu, C., Hsu, M., Sun, S., Lin, T., \& Sun, P. (2005). Usability, quality, value and e-learning continuance decisions. Computers \& Education, 45(4), 399-416. https://doi.org/10.1016/j.compedu.2004.06.001

Chiu, C., \& Wang, E. T. (2008). Understanding Web-based learning continuance intention: The role of subjective task value. Information \& Management, 45(3), 194-201. https://doi.org/10.1016/j.im.2008.02.003

Chow, W. S., \& Shi, S. (2014). Investigating students' satisfaction and continuance intention toward e-learning: An extension of the expectation - confirmation model. Procedia-Social and Behavioral Sciences, 141, 1145-1149. https://doi.org/10.1016/j.sbspro.2014.05.193

Cusumano, M. A. (2013). Are the costs of 'free' too high in online education? Communications of the ACM, 56(4), 26-28. https://doi.org/10.1145/2436256.2436264

Daniel, J. (2012). Making sense of MOOCs: Musings in a maze of myth, paradox and possibility. Journal of Interactive Media in Education, 2012(3), Article 18. https://doi.org/10.5334/2012-18

Diamantopoulos, A., Siguaw, J. A., \& Siguaw, J. A. (2000). Introducing LISREL: A guide for the uninitiated. Beverly Hills, CA: Sage Publications.

Hew, K. F., \& Cheung, W. S. (2014). Students' and instructors' use of massive open online courses 
(MOOCs): Motivations and challenges. Educational Research Review, 12(6), 45-58. https://doi.org/10.1016/j.edurev.2014.05.001

Howard, G. S. (1994). Why do people say nasty things about self - reports? Journal of Organizational Behavior, 15(5), 399-404. https://doi.org/10.1002/job.4030150505

Hu, L., \& Bentler, P. M. (1998). Fit indices in covariance structure modeling: Sensitivity to underparameterized model misspecification. Psychological Methods, 3(4), 424-453. https://doi.org/10.1037/1082-989X.3.4.424

Jacobs, A. J. (2013). Two cheers for web u! New York Times, 162(56113), 1-7. Retrieved from http://www.nytimes.com/2013/04/21/opinion/sunday/grading-the-mooc-university.html

Karahanna, E., Straub, D. W., \& Chervany, N. L. (1999). Information technology adoption across time: A cross-sectional comparison of pre-adoption and post-adoption beliefs. MIS Quarterly, 23(2), 183-213. https://doi.org/10.2307/249751

Lee, M. (2010). Explaining and predicting users' continuance intention toward e-learning: An extension of the expectation - confirmation model. Computers \& Education, 54(2), 506-516. https://doi.org/10.1016/j.compedu.2009.09.002

Li, K. M. (2015). Learning styles and perceptions of student teachers of computer-supported collaborative learning strategy using wikis. Australasian Journal of Educational Technology, 31(1), 21-50. https://doi.org/10.14742/ajet.521

Lin, C. S., Wu, S., \& Tsai, R. J. (2005). Integrating perceived playfulness into expectation-confirmation model for web portal context. Information \& Management, 42(5), 683-693. https://doi.org/10.1016/j.im.2004.04.003

Lucas, H. C. (2013). Can the current model of higher education survive MOOCs and online learning. EDUCAUSE Review, 48(5), 54-56. Retrieved from https://www.editlib.org/p/133282

Muñoz-Merino, P. J., Ruipérez-Valiente, J. A., Alario-Hoyos, C., Pérez-Sanagustín, M., \& Kloos, C. D. (2014). Precise Effectiveness Strategy for analyzing the effectiveness of students with educational resources and activities in MOOCs. Computers in Human Behavior, 47(3), 108-118. https://doi.org/10.1016/j.chb.2014.10.003

Nunnally, J. C. (2010). Psychometric theory (3th ed.). New York, NY: Tata McGraw-Hill Education.

Oliver, R. L. (1980). A cognitive model of the antecedents and consequences of satisfaction decisions. Journal of Marketing Research, 17(4), 460-469. https://doi.org/10.2307/3150499

Podsakoff, P. M., MacKenzie, S. B., Lee, J., \& Podsakoff, N. P. (2003). Common method biases in behavioral research: A critical review of the literature and recommended remedies. Journal of Applied Psychology, 88(5), 879-903. https://doi.org/10.1037/0021-9010.88.5.879

Proserpio, L., \& Magni, M. (2012). Teaching without the teacher? Building a learning environment through computer simulations. International Journal of Information Management, 32(2), 99-105. https://doi.org/10.1016/j.ijinfomgt.2011.09.002

Santhanam, R., Sasidharan, S., \& Webster, J. (2008). Using self-regulatory learning to enhance e-learning-based information technology training. Information Systems Research, 19(1), 26-47. https://doi.org/10.1287/isre.1070.0141

Spoelstra, H., van Rosmalen, P., Houtmans, T., \& Sloep, P. (2015). Team formation instruments to enhance learner interactions in open learning environments. Computers in Human Behavior, 45(4), 11-20. https://doi.org/10.1016/j.chb.2014.11.038

Spreng, R. A., MacKenzie, S. B., \& Olshavsky, R. W. (1996). A reexamination of the determinants of consumer satisfaction. The Journal of Marketing, 60(3), 15-32. https://doi.org/10.2307/1251839

Stahl, G., Koschmann, T., \& Suthers, D. (2006). Computer-supported collaborative learning: An historical perspective. In R. K. Sawyer (Eds.), Cambridge Handbook of the Learning Sciences, (pp. 409-426). New York, NY: Cambridge University Press.

Sturges, P. (2014). Some structuring principles for planning LIS qualifications in developing countries. Information Development, 30(4), 378-381. https://doi.org/10.1177/0266666914552965

Venkatesh, V., Morris, M. G., Davis, G. B., \& Davis, F. D. (2003). User acceptance of information technology: Toward a unified view. MIS Quarterly, 27(3), 425-478. Retrieved from http://www.jstor.org/stable/30036540

Wan, Z., Compeau, D., \& Haggerty, N. (2012). The effects of self-regulated learning processes on e-learning outcomes in organizational settings. Journal of Management Information Systems, 29(1), 307-340. https://doi.org/10.2753/MIS0742-1222290109

Wei, K., Teo, H., Chan, H. C., \& Tan, B. C. (2011). Conceptualizing and testing a social cognitive model of the digital divide. Information Systems Research, 22(1), 170-187. https://doi.org/10.1287/isre.1090.0273

Wheeler, S., Yeomans, P., \& Wheeier, D. (2008). The good, the bad and the wiki: Evaluating student generated content for collaborative learning. British Journal of Educational Technology, 39(6), 
987-995. https://doi.org/10.1111/j.1467-8535.2007.00799.x

Yang, Y., Heinrich, E., \& Kemp, E. (2011). Assessment of online discussion: Collecting discussion content and generating analysis data for assessment and Feedback. Paper presented at World Conference on E-Learning in Corporate, Government, Healthcare, and Higher Education, Chesapeake, VA. Retrieved from https://www.editlib.org/p/38838/

Yang, S., Lu, Y., Gupta, S., Cao, Y., \& Zhang, R. (2012). Mobile payment services adoption across time: An empirical study of the effects of behavioral beliefs, social influences, and personal traits. Computers in Human Behavior, 28(1), 129-142. https://doi.org/10.1016/j.chb.2011.08.019

Yu, A. Y., Tian, S. W., Vogel, D., \& Kwok, C. (2010). Can learning be virtually boosted? An investigation of online social networking impacts. Computers \& Education, 55(4), 1494-1503. https://doi.org/10.1016/j.compedu.2010.06.015

Yueh, H., Huang, J., \& Chang, C. (2015). Exploring factors affecting students' continued Wiki use for individual and collaborative learning: An extended UTAUT perspective. Australasian Journal of Educational Technology, 31(1), 16-31. https://doi.org/10.14742/ajet.170

Zhou, M. (2016). Chinese university students' acceptance of MOOCs: A self-determination perspective. Computers \& Education, 92, 194-203. https://doi.org/10.1016/j.compedu.2015.10.012

Zhou, J., Zuo, M., Yu, Y., \& Chai, W. (2014). How fundamental and supplemental interactions affect users' knowledge sharing in virtual communities? A social cognitive perspective. Internet Research, 24(5), 566 - 586. https://doi.org/10.1108/IntR-07-2013-0143

Corresponding author: Zhou Junjie, jjzhou@huel.edu.cn

Australasian Journal of Educational Technology @ 2017.

Please cite as: Zhou J. (2017). Exploring the factors affecting learners' continuance intention of MOOCs for online collaborative learning: An extended ECM perspective. Australasian Journal of Educational Technology, 33(5), 123-135. https://doi.org/10.14742/ajet.2914 
Appendix 1

Constructs, items, and sources

\begin{tabular}{|c|c|c|}
\hline Constructs & Items & Sources \\
\hline $\begin{array}{l}\text { Confirmation } \\
\text { with prior } \\
\text { learning } \\
\text { experience } \\
\text { (CPLE) }\end{array}$ & $\begin{array}{l}\text { My experience with using MOOCs was better than I expected } \\
\text { The service level provided by MOOCs was better than I } \\
\text { expected } \\
\text { Overall, most of my expectations from using MOOCs were } \\
\text { confirmed }\end{array}$ & $\begin{array}{l}\text { ( Alraimi, Zo, \& } \\
\text { Ciganek, 2015) }\end{array}$ \\
\hline $\begin{array}{l}\text { Knowledge } \\
\text { outcome } \\
\text { (KO) }\end{array}$ & $\begin{array}{l}\text { MOOCs learning enlarged my scope of learning beyond the } \\
\text { textbook } \\
\text { MOOCs learning helped me to become more knowledgeable } \\
\text { in the subjects } \\
\text { MOOCs learning helped me to achieve better academic results }\end{array}$ & $\begin{array}{l}\text { ( Wei, Teo, Chan, \& } \\
\text { Tan, 2011) }\end{array}$ \\
\hline $\begin{array}{l}\text { Performance } \\
\text { proficiency } \\
\text { (PP) }\end{array}$ & $\begin{array}{l}\text { I am confident about the adequacy of my academic skills and } \\
\text { abilities } \\
\text { I feel competent conducting my course assignments } \\
\text { I have learned how to successfully perform my coursework in } \\
\text { an efficient manner } \\
\text { I have performed academically as well as I anticipated I would }\end{array}$ & $\begin{array}{l}\text { ( Yu, Tian, Vogel, } \\
\text { \& Kwok, 2010) }\end{array}$ \\
\hline $\begin{array}{l}\text { Satisfaction } \\
\text { with prior } \\
\text { learning } \\
\text { (SATIS) }\end{array}$ & $\begin{array}{l}\text { In most ways my experience in MOOCs is close to my ideal } \\
\text { The conditions of my experience in MOOCs are excellent } \\
\text { So far I have gotten the important things I want in MOOCs } \\
\text { I am satisfied with my experience in MOOCs }\end{array}$ & $\begin{array}{l}\text { ( Yu, Tian, Vogel, } \\
\text { \& Kwok, 2010) }\end{array}$ \\
\hline $\begin{array}{l}\text { Social } \\
\text { influence (SI) }\end{array}$ & $\begin{array}{l}\text { People around me who use MOOCs have more prestige than } \\
\text { those who do not } \\
\text { People who use MOOCs have a high profile } \\
\text { Using MOOCs is considered a status symbol among my } \\
\text { friends } \\
\text { My friends think that I should keep use MOOCs }\end{array}$ & $\begin{array}{l}\text { (Yang, Lu, Gupta, } \\
\text { Cao, \& Zhang, 2012) }\end{array}$ \\
\hline $\begin{array}{l}\text { Learners' } \\
\text { continuance } \\
\text { intention } \\
\text { (LCI) }\end{array}$ & $\begin{array}{l}\text { I intend to continue using MOOCs in the future } \\
\text { I will continue using MOOCs in the future } \\
\text { I will strongly recommend MOOCs for others to use it } \\
\text { I will keep using MOOCs as regularly as I do now }\end{array}$ & $\begin{array}{l}\text { ( Alraimi, Zo, \& } \\
\text { Ciganek, 2015) }\end{array}$ \\
\hline
\end{tabular}

